\title{
Analysis of China's Industrial smoke and dust Emissions
}

\author{
Ying $\mathrm{He}^{1, a}$, Cuishu Sun ${ }^{1, b^{*}}$ and Yijun $\mathrm{Ji}^{2, \mathrm{c}}$ \\ ${ }^{1}$ School of Tianjin University of Technology, Tianjin 300191, China; \\ ${ }^{2}$ School of Nankai University, Tianjin 300071, China. \\ atjheying@126.com, ${ }^{\text {b }}$ suncuishu@126.com, ${ }^{\text {Cjijijun@nankai.edu.cn }}$
}

\begin{abstract}
Keywords: Industry, Smoke and dust emissions, Industrial structure.
Abstract. With the use of environmental statistics, this paper studied the industrial structure of China's smoke and dust emissions. Meanwhile, it analyzed the changes of waste gas emissions, smoke and dust emissions and smoke and dust emission concentration of the six key industries, namely, the power, steel, building materials, chemical, nonferrous metal and petrochemical coking industries, as well as mining industry in 2014 in comparison with the condition of 2005 . The aim is to provide a reference for the scientific determination of the main orientation of $\mathrm{SO}_{2}$ emission reduction in China.
\end{abstract}

\section{Introduction}

Particulate matter is the main pollutant restraining the air quality in China. In 2015, among the days when the urban air quality standard was exceeded, $66.8 \%$ and $15.0 \%$ were contributed by the days when $\mathrm{PM}_{2.5}$ and $\mathrm{PM}_{10}$ were the primary pollutant respectively, which accounted for a total of $81.8 \%$, far more than the days when $\mathrm{O}_{3}, \mathrm{NO}_{2}$ and other pollutants were the primary pollutant. And the industrial smoke and dust are the main source of $\mathrm{PM}_{10}$ as well as an important component of $\mathrm{PM}_{2.5}$. They have made a considerable contribution to air pollution. Moreover, smoke and dust will also affect public health. Studies have shown that the increase in $\mathrm{PM}_{10}$ concentration can lead to an increase in the total mortality, respiratory system, cardiovascular and cerebrovascular disease mortality of Chinese population ${ }^{[1]}$; WHO's International Agency for Research on Cancer has listed $\mathrm{PM}_{10}$ into the first class of carcinogens ${ }^{[2]}$.

As the largest source of smoke and dust in China, industry accounts for more than $80 \%$ of the total smoke and dust emissions. This paper analyzed the industrial structure of the smoke and dust emissions in China. The aim is to provide a reference for the scientific determination of the mainorientation of smoke and dust emission reduction in China.

\section{Industrial Structure of Smoke and Dust Emission in China}

Smoke and dust emission amount of each industrial sector in China and their respective proportion in the total industrial emission amount in 2014 are shown in Table 1 and Fig.1.Different Chinese industrial sectors have remarkably different amounts of smoke and dust emissions, of which smoke and dust is mainly emitted by the following seven key industries: 42 (hereinafter referred to as power industry), 31 (hereinafter referred to as steel industry), 30 (hereinafter referred to as building materials industry), 32 (hereinafter referred to as chemical industry), 25 (hereinafter referred to as nonferrous metals industry), 26 (hereinafter referred to as petrochemical and coking industry) and 6(hereinafter referred to as mining industry). The previous six industrial sectors are commonly referred to as "the six key industries" by national statistical offices. In 2014, the seven key industries discharged a total of 11.49 million tons of smoke and dust, accounting for $90.6 \%$ and $66 \%$ of the total industrial and national smoke and dust emissions respectively according to the statistics. Among the seven key industries, steel industry contributed to largest smoke and dust emissions. It was followed by power industry and building materials industry. The next two were chemical industry and petrochemical and coking industry. At last, nonferrous metals industry and coal mining industry emitted the least smoke and dust among the seven key industries. 
Table1 Smoke and dust emissions of China's industrial sectors and their proportions in 2014.

\begin{tabular}{ccccccccc}
\hline Code & Total $/ 10^{3} \mathrm{t}$ & Proportion & Code & Total/ $10^{3} \mathrm{t}$ & Proportion & Code & Total/ $10^{3} \mathrm{t}$ & Proportion \\
\hline 6 & 385.1 & 3.04 & 19 & 11.2 & 0.09 & 32 & 384.8 & 3.04 \\
7 & 7.9 & 0.06 & 20 & 128.0 & 1.01 & 33 & 70.1 & 0.55 \\
8 & 94.4 & 0.74 & 21 & 2.7 & 0.02 & 34 & 25.3 & 0.20 \\
9 & 20.4 & 0.16 & 22 & 141.8 & 1.12 & 35 & 17.5 & 0.14 \\
10 & 52.7 & 0.42 & 23 & 3.3 & 0.03 & 36 & 39.0 & 0.31 \\
11 & 1.4 & 0.01 & 24 & 1.8 & 0.01 & 37 & 6.6 & 0.05 \\
12 & 0.9 & 0.01 & 25 & 421.4 & 3.32 & 38 & 6.7 & 0.05 \\
13 & 163.1 & 1.29 & 26 & 658.2 & 5.2 & 39 & 0.7 & 0.01 \\
14 & 64.9 & 0.51 & 27 & 48.8 & 0.38 & 40 & 31.1 & 0.25 \\
15 & 63.7 & 0.50 & 28 & 32.2 & 0.25 & 41 & 8.4 & 0.07 \\
16 & 5.8 & 0.05 & 29 & 38.1 & 0.30 & 42 & 2724.2 & 21.5 \\
17 & 83.5 & 0.66 & 30 & 2644.9 & 20.9 & 43 & 5.2 & 0.04 \\
18 & 10.5 & 0.08 & 31 & 4271.8 & 33.7 & 44 & 0.0 & 0.00 \\
\hline
\end{tabular}

Note: Industry codes in the table are the category codes in the Classification of National Economy (GB/T 4754-2011), for example, 06 for coal mining and washing industry and 07 for oil and gas extraction industry.

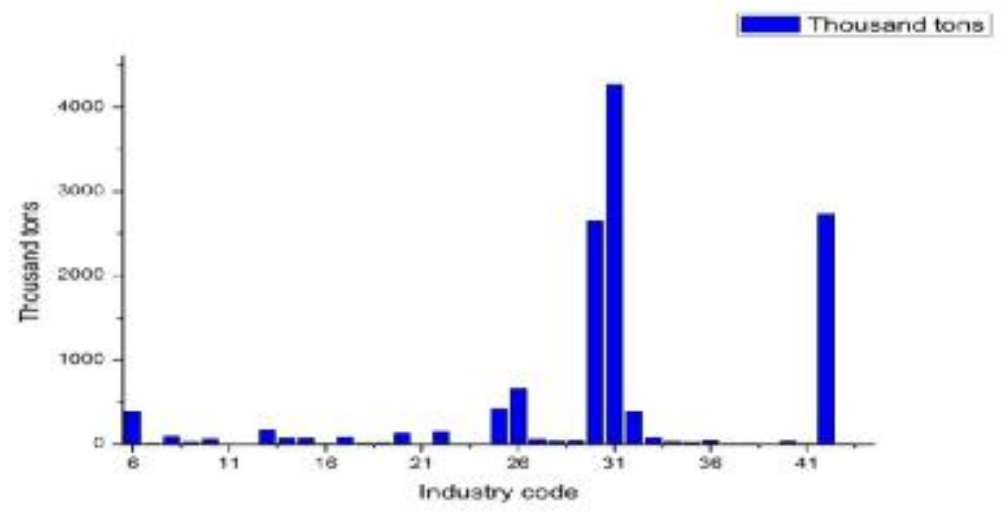

Fig.1 Smoke and dust emission amount of each industrial sector in China in 2014

\section{Changes in Smoke and Dust Emissions of Key Industries and Their Contribution to the Whole Industrial Smoke and Dust Emission Reductions}

Whether each sector has reduced its emissions or not? What are the changes of their emission reduction rates during this decade? Which sector has made the greatest contribution to the reduction in industrial emissions? Answers can be found by comparing the smoke and dust emission reduction status of the seven key industries in 2005 and that in 2014. Thus, the paper calculated the smoke and dust emissions of the seven key industries and analyzed their contribution to the whole industrial smoke and dust emission reductions and the national smoke and dust emission reductions, which is shown in Table 2.

It can be seen from Table 2 that compared with 2005, the seven key industries reduced 3.63 million tons of smoke and dust emission in 2014, accounting for $91.35 \%$ and $102.87 \%$ of the whole industrial and national smoke and dust emission reductions respectively. This can indicate their decisive role in smoke and dust emission reductions. Most of the reductions were made by building materials industry whose emission reduction amount and rate were 4.35 million tons and $62.19 \%$ respectively, accounting for $109.48 \%$ and $123.29 \%$ of the whole industrial and national smoke and dust emission reductions respectively. The following was power industry whose emission reduction amount and rate were 1.44 million tons and $34.51 \%$ respectively, accounting for $36.12 \%$ and $40.68 \%$ of the whole industrial and national smoke and dust emission reductions respectively. The emission reduction amount and rate of petrochemical and coking industry and 
chemical industry were 148.8 thousand tons, $26.1 \%, 52.7$ thousand tons and $7.41 \%$ respectively, and their contribution rates to industrial and national smoke and dust emissions were $3.74 \%$ and $1.33 \%$ respectively. On the contrary, for steel industry, nonferrous metals industry and mining industry, the amount of smoke and dust emissions was not reduced, especially steel industry.

Table 2 Smoke and dust emissions of the seven key industries in 2005 and 2014.

\begin{tabular}{|c|c|c|c|c|c|c|c|c|}
\hline \multirow[b]{2}{*}{ Sector } & \multicolumn{2}{|c|}{2005} & \multicolumn{2}{|c|}{2014} & \multicolumn{3}{|c|}{$2014-2005$} & \multirow[b]{2}{*}{$\begin{array}{c}\text { Contribution } \\
\text { to national } \\
\text { emission } \\
\text { reductions }\end{array}$} \\
\hline & $\begin{array}{l}\text { Total } / 10 \\
3_{t}\end{array}$ & $\begin{array}{l}\text { Proporti } \\
\text { on }\end{array}$ & $\begin{array}{l}\text { Total } / 10 \\
3_{t}\end{array}$ & $\begin{array}{l}\text { Proporti } \\
\text { on }\end{array}$ & $\begin{array}{c}\text { Emissio } \\
\mathrm{n} \\
\text { reducti } \\
\text { on } / 10^{3} \mathrm{t}\end{array}$ & $\begin{array}{l}\text { Emissi } \\
\text { on } \\
\text { reducti } \\
\text { on rate }\end{array}$ & $\begin{array}{c}\text { Contributionto } \\
\text { industrial } \\
\text { emission } \\
\text { reductions }\end{array}$ & \\
\hline $\begin{array}{l}\text { Building } \\
\text { Materials }\end{array}$ & 6995.9 & 42.01 & 2644.9 & 20.86 & 4351.0 & 62.19 & 109.48 & 123.29 \\
\hline Power & 4159.9 & 24.98 & 2724.2 & 21.49 & 1435.7 & 34.51 & 36.12 & 40.68 \\
\hline $\begin{array}{l}\text { Petrochemic } \\
\text { al andcoking }\end{array}$ & 570.2 & 3.42 & 421.4 & 3.32 & 148.8 & 26.1 & 3.74 & 3.22 \\
\hline Chemical & 710.9 & 4.27 & 658.2 & 5.19 & 52.7 & 7.41 & 1.33 & 1.49 \\
\hline Steel & 1949.5 & 11.71 & 4271.8 & 33.69 & -2322.3 & -119.12 & -58.43 & -65.81 \\
\hline Nonferrous & 379.3 & 2.28 & 384.8 & 3.04 & -05.5 & -1.45 & -0.14 & -0.16 \\
\hline Mining & 355.2 & 2.13 & 385.1 & 3.04 & -29.9 & -8.43 & -0.75 & -0.85 \\
\hline Total & 15120.9 & 90.8 & 11490.4 & 90.63 & 3630.5 & 21.8 & 91.35 & 102.87 \\
\hline
\end{tabular}

In summary, from 2005 to 2014, seven key industries played a decisive role in industrial and national smoke dust emission reductions. However, in fact, among the seven key industries, building materials industry and power industry played a main positive decisive role, while steelindustry whose emissions increased significantly obviously impeded the reduction of industry and the national smoke and dust emissions.

\section{Analysis of the Relationship among Smoke and Dust Emissions, Waste Gas Emission and Emission Concentration of the Key Industries}

Smoke and dust emissions of various industries depend on their emission amount of waste gas and smoke and dust emission concentration. Therefore, the paper analyzed changes of waste gas emissions and smoke and dust emission concentration of the seven major sectors in 2005 and 2014, so as to analyze the reason for the changes in smoke and dust emissions of each key industry, as shown in Table 3.

As can be seen from Table 3, compared with 2005, the emission amounts of waste gas of the key industries all increased significantly in 2014 except for mining industry, while the average smoke and dust emission concentration dropped obviously with specific drop ranges being different in different industries. The emission growth rate of steel industry was as high as $223.36 \%$, remarkably higher than that of the other six key industries, while its emission concentration reduction rate was only $32.23 \%$, significantly lower than that of the other five key industries. This was caused by its notably increased smoke and dust emissions. However, the smoke and dust emission reduction rates of building materials industry and power industry were prominently higher than that of other key industries, while their emission growth rates were relatively low. This was caused by significant reductions in their emission amounts. Mining industry emissions showed a much lower increase rate than the other six key industries did, but its emission concentration remained basically unchanged, so its smoke and dust emissions increased. 
Table 3Smoke and dust emission concentration of the seven key industries in 2005 and 2014.

\begin{tabular}{|c|c|c|c|c|c|c|c|c|c|}
\hline \multirow{2}{*}{ Sector } & \multicolumn{3}{|c|}{$\begin{array}{l}\text { Waste gas emissions } \\
\left(10^{8} \mathrm{Nm}^{3}\right)\end{array}$} & \multicolumn{3}{|c|}{$\begin{array}{l}\text { Smoke and dust emissions } \\
\left(10^{3} \mathrm{t}\right)\end{array}$} & \multicolumn{3}{|c|}{$\begin{array}{c}\text { Smoke and dust emission concentration } \\
\left(\mathrm{mg} / \mathrm{Nm}^{3}\right)\end{array}$} \\
\hline & 2005 & 2014 & $\begin{array}{l}\text { Change } \\
\text { rate }(\%)\end{array}$ & 2005 & 2014 & $\begin{array}{l}\text { Change } \\
\text { rate }(\%)\end{array}$ & 2005 & 2014 & $\begin{array}{l}\text { Change } \\
\operatorname{rate}(\%)\end{array}$ \\
\hline \multirow{3}{*}{$\begin{array}{l}\text { Building } \\
\text { Materials } \\
\text { Power } \\
\text { Petroche } \\
\text { mical } \\
\text { andcokin } \\
\text { g }\end{array}$} & 4986.0 & 12846.0 & 157.64 & 6995.9 & 2644.9 & -62.19 & 1403.11 & 205.89 & -85.33 \\
\hline & 8834.7 & 21509.4 & 143.46 & 4159.9 & 2724.2 & -34.51 & 470.86 & 126.65 & -73.10 \\
\hline & 912.9 & 2129.1 & 133.22 & 570.2 & 421.4 & -26.1 & 624.60 & 197.92 & -68.31 \\
\hline \multirow{3}{*}{$\begin{array}{l}\text { Chemical } \\
\text { Steel } \\
\text { Nonferro }\end{array}$} & 1588.7 & 4178.3 & 163.00 & 710.9 & 658.2 & -7.41 & 447.47 & 157.53 & -64.80 \\
\hline & 5619.0 & 18169.4 & 223.36 & 1949.5 & 4271.8 & 119.12 & 346.95 & 235.11 & -32.23 \\
\hline & 1318.3 & 3616.6 & 174.34 & 379.3 & 384.8 & 1.45 & 287.72 & 106.40 & -63.02 \\
\hline \multirow[t]{2}{*}{ Mining } & 193.5 & 208.8 & 7.91 & 355.2 & 385.1 & 8.43 & 1835.66 & 1844.58 & 0.49 \\
\hline & Accord & to the a & re analy & from & 005 to & $14, \mathrm{C}$ & a's indus & $\begin{array}{l}\text { smoke } \\
\text { centratio } \\
\text { he small } \\
\text { us of steel }\end{array}$ & $\begin{array}{l}\text { ust } \\
\text { key } \\
\text { ion } \\
\text { try }\end{array}$ \\
\hline
\end{tabular}

\section{Conclusions}

In the paper, the industrial structure of industrial smoke and dust emission in seven key industries in China was analyzed. Besides, the changes in smoke and dust emissions, emission concentration and waste gas emission in the seven key industries in 2005 and 2014 were calculated and compared. Three conclusions were drawn in the study as follows. Firstly, in2014, the smoke and dust emissions from the seven high-polluting sectors of steel, electricity, building materials, chemical, petrochemical and coking, mining and nonferrous industries accounted for $90.63 \%$ of the total industrial emissions and $66 \%$ of the total national emissions. Secondly, among the seven key industries, building materials industry and power industry, as the key to smoke and dust emission reductions, reduced emission amounts of 4.35 million tons and 1.44 million tons respectively, and contributed reduction rates of $109.48 \%$ and $36.12 \%$ respectively to industrial smoke and dust emission reductions and $123.29 \%$ and $40.68 \%$ respectively to national smoke and dust emission reductions. In contrast, the smoke and dust emissions of steel industry increased significantly. Obviously, it impeded the reduction of industrial and national smoke and dust emissions. Thirdly, from 2005 to 2014, the smoke and dust emissions of steel industry increased mainly due to its high emission growth rate of $223.36 \%$ whichwas significantly higher than that of the other six key industries; whereas, its reduction rate of emission concentration was only $32.23 \%$, which was notably lower than that of the other five key industries. The remarkable decrease of emission reductions of power industry resulted from its great reduction rate of emission concentration, which was significantly higher than that of other key industries.

\section{Acknowledgments}

This study was supported by the Natural Science Foundation of Tianjin, China (No. 13JCQNJC08300) 


\section{References}

[1] Jin Man, Tian Lu. Meta-analysis of the Influence of Atmospheric PM10 Pollution on Population Mortality in China [J].Journal of Environment and Health, 2016, 33 (8): 725-729.

[2] Dana Loomis, Huang Wei, et al. Analysis of Carcinogenicity of Outdoor Air Pollution in China Made by IARC [J]. Chin J Cancer, 2014, 33 (4): 189-196. 